\title{
DISCURSOS SOBRE INMIGRACIÓN INTERNACIONAL EN CHILE QUE DEVELAN RACISMO ${ }^{1}$
}

\author{
Speeches on International Immigration in Chile that Reveal Racism \\ Martina Cociña Cholaki \\ CONICYT \\ martinacoci@gmail.com
}

\begin{abstract}
Resumen:
Este artículo analiza discursos de autoridades chilenas pronunciados a propósito de la eclosión migratoria internacional experimentada en dicho país en el último decenio, específicamente se estudian las retóricas empleadas por políticos que dan cuenta de racismo, en tanto visualizan a quienes arriban desde un sitial de superioridad, apartándolos, enfatizando su no pertenencia y su exclusión como sujetos de derechos. Así se examina cómo en Chile determinadas autoridades les adosan a ciertos extranjeros suciedad, ruido, costumbres reñidas con la moral, estigmatizándolos y transformándolos en culpables de las más diversas falencias sociales. Desde esta construcción se naturaliza su discriminación, de allí la relevancia de denunciar estos discursos falaces que fomentan una ciudadanía precarizada.
\end{abstract}

\section{Palabras clave:}

discursos, inmigración, racismo, Chile

\begin{abstract}
:
This paper analyzes speeches by Chilean authorities on the subject of the international migratory hatching experienced in that country in the last decade, specifically the rhetorics used by politicians who account for racism are studied, while they visualize those who arrive from a place of superiority, separating them, emphasizing their non-belonging and their exclusion as subjects of rights. Thus it is examined how in Chile certain authorities attach to certain foreigners dirt, noise, customs at odds with morality, stigmatizing them and transforming them into guilty of the most diverse social failures. From this construction their discrimination is naturalized, hence the relevance of denouncing these fallacious speeches that foster a precarious citizenship.
\end{abstract}

\footnotetext{
${ }^{1}$ Este artículo ha sido desarrollado en el marco de la investigación doctoral "El tratamiento de la Inmigración en Chile", financiado gracias al programa de Becas Chile en el extranjero, CONICYT y se basa en lo planteado en la tesis de máster "Aproximación al tratamiento de la inmigración en Chile".
} 


\section{Keywords:}

Speeches, Inmigration, Racism, Chile

Recibido: 05/12/2019

Aceptado: 20/12/2019

\section{MARCO TEÓRICO: RACISMO}

Como apunta Wieviorka, el racismo responde a la "presencia de la idea de un vínculo entre los atributos o el patrimonio- físico, genético o biológico- de un individuo (o de un grupo) y sus caracteres intelectuales y morales" (1992: 17). El racismo constituye una ideología en que se inferioriza y se produce la diferenciación del otro, en la medida que se excluye y se rechaza la alteridad, es decir, corresponde a una "antropología de la desigualdad en función de la cual poblaciones enteras o categorías de personas pueden ser destruidas por ser consideradas humanamente inferiores y privadas de identidad y de la dignidad como personas" (Ferrajoli, 2014: 87).

Hoy en día la figura del migrante en tanto conlleva una mirada racializada del otro, se establece como la continuidad de la raza, los extranjeros son los nuevos bárbaros, seres vivos que desafían el razonamiento identitario y las costumbres del orden de la nación. Quienes se desplazan se instituyen en los nuevos enemigos imaginarios de la patria, así los discursos relativos a su presencia no permiten más que subrayar las diferencias entre los de dentro y los de allá e impulsar políticas de exclusión (Silveira, 2012; Tijoux y Díaz, 2014).

Actualmente se está en presencia de una evolución del racismo, donde el fundamentalismo cultural justifica la exclusión de ciertos foráneos, no por causas biológicas, sino debido a que algunos extranjeros se visualizan como una amenaza a la patria, a la cultura y/o a la identidad nacional (Póo, 2009; Silveira, 1996). De este modo se justifica el desprecio hacia aquellos sujetos que pudiesen constituir un peligro.

Bajo este discurso que se generaliza en la sociedad contemporánea se esconde un racismo diferencialista que más que comprender al otro, lo aparta en su diferencia. En igual sentido, como arguye Liberona, la alterización de quienes se movilizan "legitima y perpetúa la dominación étnica y de clase, produciendo discriminaciones hacia los inmigrantes. Esto se ve reforzado por la decisión de asumir un trato culturalista hacia las poblaciones extranjeras" (2015b: 11).

Entonces, en torno a la noción de racismo se construye la idea de que existen unos seres inferiores que por su condición deben encontrarse sometidos a sujetos estimados superiores. Precisamente, "la separación cognitiva entre nosotros y ellos implica una evaluación en términos de superiores o inferiores" (Van Dijk, 1988: 165). 
El racismo moderno "moviliza los síndromes clásicos de peligro y pureza, y actúa como una suerte de defensa de las fronteras del grupo primario contra esa amenaza que se percibe como inherente a la existencia misma del Otro" (Jameson, 1998: 105). Temores que se exacerban en ciertos grupos de chilenos que abogan por la "pureza de la patria", basándose en una supuesta superioridad del nacional sobre ciertos extranjeros y en las consecuencias negativas que generaría la presencia foránea. En efecto, se trata de una retórica política en que se inscribe la sociedad y que hace de la diferencia cultural la justificación de las políticas de seguridad y de control (Correa, 2011; Márquez y Correa, 2015).

Por tanto, el Estado nacional moderno "es esencialmente civilizacional (se define contra los bárbaros en sentido colonial) y racista (se define contra la heterogeneidad racial en sentido racista-estatal)" (Tijoux y Díaz, 2014: 299), de ahí que el racismo sea uno de los pilares centrales de su construcción, fundado en el imaginario de la etnicidad ficticia de la comunidad entendida como nación. Esta falaz configuración, en parte, se explica por retóricas de autoridades que no hacen más que subrayar las diferencias entre los chilenos y los foráneos, enfatizando la no pertenencia de los segundos y fomentando su exclusión, un imaginario social que a pesar de no tener asidero en la realidad cala fuertemente en grandes capas de la población.

Esta dinámica fomenta un tratamiento diferenciado en el ejercicio de los derechos, lo que se traduce en una gestión de los flujos de personas que en vez de realizar un reconocimiento de las garantías de quienes se desplazan, los conciben como ciudadanos de segunda o tercera clase, es decir, sujetos que pueden permanecer en el país de destino pero sin gozar de los derechos de los "autóctonos". De allí que se hable de ciudadanía precarizada en la medida que se asume que no tienen las mismas garantías que los nacionales ni debiesen aspirar a aquello, en tanto, más que concebirlos desde el principio de la igualdad, se perpetúa la definición en torno a la no pertenencia, remarcando las diferencias y la imposibilidad de integración real.

2. CONTEXTO NACIONAL: TENDENCIAS MIGRATORIAS, MARCO NORMATIVO Y NEOLIBERALISMO

\subsection{TENDENCIAS MIGRATORIAS}

Históricamente en Chile se han reconocido tres períodos relevantes en cuanto a corrientes migratorias. La primera fomentada por el Estado oligárquico-liberal a mediados del siglo XIX para atraer preferentemente colonos europeos a tierras del sur; el segundo momento histórico correspondió a la emigración política producto de la dictadura cívico militar que obligó a miles de compatriotas a solicitar asilo al exterior, y la última y más reciente, situada desde los noventa en adelante consistente en las movilizaciones de personas, especialmente intrarregionales, hacia Chile. Esta última corriente es la que se examinará en este artículo, en especial la última década, debido a que el porcentaje de extranjeros residiendo permanentemente se ha incrementado notoriamente, pasando en menos de siete 
años, del 2009 al 2015, a representar de un 1,3\% a un 2,7\% de la población nacional y actualmente constituyen el $6,6 \%{ }^{2}$.

\subsection{MARCO NORMATIVO}

El marco jurídico migratorio actual data de la dictadura, el principal cuerpo regulador consiste en un decreto ley dictado en 1975 (DL 1094), imbuido de la Doctrina de Seguridad Nacional que concibe al foráneo como un enemigo, de allí que la política que establezca sea meramente restrictiva. El paradigma migratorio en que se encuentra inserto el marco normativo vigente en Chile se sustenta en tres pilares esenciales: el primero, asume que la migración es un atributo exclusivo del Estado, el segundo, visualiza la movilidad humana como una amenaza; $y$, el tercero, considera que imponiendo requisitos determina quien ingresa. Bajo esta percepción, la legislación marco establece una serie de restricciones a la entrada y permanencia de extranjeros, lo que finalmente se plasma en la legitimación institucional a diversas prácticas discriminatorias y abusivas respecto de quienes transitan. Por ende, constituye una regulación que al centrarse en la gestión burocrática de los desplazamientos genera paradójicamente más situaciones de irregularidad.

Por consiguiente, en esta materia rige una regulación discriminatoria con un fuerte enfoque policial, orientada al control y a la seguridad y que le entrega amplio margen de discrecionalidad a las fuerzas de seguridad (Zavala y Rojas, 2005). Una legislación que más que integrar a aquél que viene en búsqueda de una mejor vida, le impone trabas y requerimientos, así fomenta la vulnerabilidad de quien arriba. En otros términos, en esta nación rige una ley migratoria que más que fomentar la inclusión, se instaura con la finalidad de discriminar a ciertas personas, debido a un factor aleatorio como es el hecho de haber nacido en un país distinto. Entonces, la norma más que resguardar las garantías de quienes se movilizan, se establece como el instrumento que posibilita su exclusión.

\subsection{NeOliberalismo}

Para poder comprender cómo en este país se insertan los discursos de carácter racista respecto a la inmigración es menester no olvidar que en Chile el neoliberalismo se aplicó en profundidad, pues luego de la denominada "vía pacífica al socialismo", la dictadura cívico-militar instauró uno de los regímenes más cruentos que junto al terror y la represión, liberalizó la economía en sus más amplios términos. No por nada, esta nación fue conocida como el experimento neoliberal por excelencia. Milton Friedman lo denominó el "milagro económico", este apodo con que el economista lo calificó, no consideró u obvió deliberadamente las consecuencias que trajo consigo implementar un modelo que al reforzar las inequidades existentes deja a un porcentaje no menor de la población excluida.

Este modelo ha ocasionado la destrucción de la vida política y el triunfo de la cultura del individualismo, instaurando la eficacia como principio central de la vida, el imperativo de producir constantemente, de maximizar sin límite alguno. Como

\footnotetext{
${ }^{2}$ Estimación del Departamento de extranjería y migración a diciembre de 2018. Para mayor información vid:: <https://www.migracionenchile.cl/poblacion> Consultado el 19 de diciembre de 2019.
} 
sintetiza Díaz, en Chile se "subordina el derecho y la democracia a la economía, a un capitalismo salvaje y destructivo" (2015: 10), un sistema excluyente que ha generado un descontento social tan profundo, que en la actualidad se expresa en masivas protestas.

El neoliberalismo es un sistema estructuralmente excluyente, que fomenta la inequidad, la marginalidad y el endeudamiento de sectores importantes de la población; no obstante, cómo se examinará ciertos políticos chilenos en lugar de criticarlo y propender a la construcción de un modelo que garantice los derechos esenciales de todos, prefieren endosarle los problemas a quienes arriban, individuos que por ser "originariamente" ajenos a "la comunidad", no es difícil culpabilizarlos. Por eso, como sostienen Gissi, Galaz y Facuse, en Chile "el egoísmo individual se refuerza así con el nacionalismo, convirtiéndose los migrantes en un chivo expiatorio de los temores característicos de individuos que viven en sociedades neoliberales ${ }^{\prime \prime}$.

\section{MetodoloGía}

Al ser un trabajo cualitativo no empírico, se examinó la literatura especializada y lo que los diversos medios de comunicación social han publicado al respecto, tanto lo disponible en prensa, radio y televisión. Asimismo lo publicado por colectivos y personas que trabajan con migrantes. Dichos documentos y noticias permitieron fundamentar el modo en que ciertas autoridades en Chile abordan la movilidad humana, en especial aquellas figuras públicas que con sus declaraciones develan una lógica racista.

Este artículo metodológicamente se nutre de presupuestos del análisis del discurso, que plantea que una totalidad significativa que puede estar formada tanto por componentes lingüísticos como extralingüísticos. Precisamente el enfoque teórico del "Análisis crítico del discurso" de Fairclough ha sido de utilidad para comprender el discurso como una práctica social bidireccional, configurado por las relaciones, las instituciones y las estructuras sociales que le dan sustento (Fairclough y Wodak, 2000). Esta corriente invita a investigar el discurso como práctica social, es decir, considerando el uso lingüístico como un modo de acción situado histórica y socialmente. Como arguye Fairclough (2008) el discurso es constitutivo, tanto de identidades sociales, como de relaciones sociales y también como sistema de conocimiento, de allí que se reconozca que en la época contemporánea hay una variedad de prácticas discursivas que coexisten y se contrastan entre sí.

Fundamentándose en Althusser y Foucault, entre otros, este enfoque plantea que el discurso cumple un papel trascendental en la reproducción de las relaciones de poder y de las identidades sociales, por ende, se debe propender a una conciencia crítica del lenguaje, que lo comprenda, como "un recurso en las luchas contra la explotación y la dominación" (Fairclough, 2008: 171).

3 Cf. "A un año de la Reforma Migratoria: Balance y proyecciones desde un Chile pluricultural poco inclusivo" Consultado el 19 de diciembre de 2019 en <https://www.eldesconcierto.cl/2019/04/21/a-un-ano-de-la-reforma-migratoria-balance-yproyecciones-desde-un-chile-pluricultural-poco-inclusivo/>. 


\section{DISCURSOS SOBRE INMIGRACIÓN INTERNACIONAL QUE EXPRESAN RACISMO}

Como arguye Liberona, "los discursos políticos son referencias significativas" (2015a: 59), por eso la necesidad de examinar los mismos y dar cuenta de cómo contribuyen a la conformación de un determinado imaginario referente a los desplazamientos internacionales de personas. En Chile, en especial en los últimos años se ha asumido que los foráneos son causantes del aumento de la delincuencia, del tráfico de drogas, de la violencia, de la prostitución, y, en fin, las más diversas problemáticas sociales. Rodríguez y Cuadra alertan que esta mirada "ha sido alentado por prominentes figuras políticas que han hecho gala de este oportunista discurso anti-migrante ${ }^{\prime \prime}$, lo que se observa a continuación en declaraciones de diversas autoridades.

\subsection{Presidente de la República}

En diversas ocasiones el presidente Sebastián Piñera ha vinculado la movilidad humana a riesgos, manifestando una visión restrictiva de ciertos desplazamientos, concibiéndolos como amenazas a la nación. Se trata de una narrativa que el actual gobierno ha empleado con el objeto de trazar un horizonte que asocia a foráneos a problemáticas como irregularidad, delincuencia, desempleo, etc. "Culpar a los extranjeros del crimen, la desigualdad, y todos los males sociales, es una vieja táctica para exculpar a los verdaderos culpables de estas crisis $^{\prime \prime}{ }^{5}$, para evitar la discusión de fondo, de un sistema estructuralmente excluyente, que segrega a los individuos según el poder adquisitivo que poseen, que asume el individualismo como el motor del modelo y desecha el rol del Estado como garante de derechos esenciales.

Bajo este enfoque, el año 2018 el mandatario y el ministro de Hacienda responsabilizaron a quienes arriban de la cesantía existente en este país, "señalaron ante un aumento en el desempleo que la causa eran los migrantes" ${ }^{\prime \prime}$. El Presidente de la República para justificar el incumplimiento de una de las promesas de su campaña, esto es, la creación de nuevos empleos, literalmente afirmó que "Ilegaron a Chile 700 mil personas que antes no estaban, que son los migrantes y eso provocó una enorme expansión de la gente que busca trabajo, por eso nosotros decidimos

\footnotetext{
${ }^{4}$ Cf. "Migración en Chile: un Ilamado de atención" de Natalia Ramírez y Gonzalo Cuadra, publicada en "El Mostrador" el 13.12.17. Consultado el 5 de diciembre de 2019 en $<$ https://www.elmostrador.cl/noticias/opinion/2017/12/13/migracion-en-chile-un-Ilamado-deatencion/>.

5 Cf. "Pinera contra los inmigrantes", consultado el 5 de diciembre de 2019 en $<$ http://elporteno.cl/2018/12/20/pinera-contra-los-inmigrantes/>.

${ }^{6}$ Cf. "Migrantes o migración: cuando el miedo le gana a la verdad", consultado el 5 de diciembre de 2019 en <https://www.elmostrador.cl/destacado/2019/01/09/migrantes-omigracion-cuando-el-miedo-le-gana-a-la-verdad/>.
} 
poner orden en la casa y regular la migración" ${ }^{\prime \prime}$. De este modo el Jefe de Estado pretendía explicar los datos que daban cuenta que se mantenía la cesantía.

Como informa la prensa, en el segundo gobierno de Sebastián Piñera "la creación de puestos de trabajo solo ha marcado un $0,5 \%$, dejando un desempleo en un $7.1 \%^{\prime \prime}$, por eso el mandatario para resguardarse de la opinión pública y no seguir descendiendo en aprobación, apuesta por endosarle la responsabilidad a los foráneos, en vez de asumir que en Chile se ha producido la desaceleración de la economía y la menor generación de empleo, intenta justificar la mala gestión económica fomentando los prejuicios. Una retórica que no debiese sorprender, considerando que durante su campaña presidencial en diversas ocasiones como se analizará, utilizó a los migrantes como "blanco de ataque".

\subsection{CANDIDATOS PRESIDENCIALES}

Diversos candidatos a la presidencia, durante las campañas electorales se han valido de quienes se desplazan para culparlos de ciertas problemáticas sociales. Quienes han hecho uso de esta retórica no necesariamente representan a partidos políticos conservadores, sino declaraciones que convierten a los migrantes en chivos expiatorios es posible apreciarlas en toda la índole política, tal como se observa a continuación.

En junio del 2013 Pablo Longueira, candidato a presidente del partido Unión Demócrata Independiente (partido de derecha), acusó a los extranjeros de obtener fuentes laborales que podrían tener los nacionales. Manifestó literalmente que "no nos oponemos a que ingresen obviamente extranjeros al país, pero lo harán con una nueva ley inmigratoria, porque necesitamos que el desarrollo económico lo disfruten primero los chilenos". Esa preponderancia que plantea Longueira en el disfrute de los derechos no se condice con el principio de igualdad que proclama toda democracia que se precie de tal.

Como arguye Thayer, "lo que hace Longueira es poner en práctica algo que la ultra derecha europea viene haciendo desde hace décadas: convertir a los migrantes en un "chivo expiatorio" ${ }^{\prime \prime}$. Es el tradicional discurso conservador, de que los que llegan están obteniendo fuentes de trabajo que podrían tener los nacionales, que están usando la infraestructura de salud y de educación pública, espacios que no les corresponderían utilizar. Ello a pesar de que en situación de regularidad los foráneos deben cotizar en el sistema de salud, público o privado y en el sistema previsional. Las palabras del entonces candidato presidencial denotan una ignorancia no menor,

\footnotetext{
${ }^{7}$ Cf. "El desempleo se mantiene y Piñera culpa a los migrantes", consultado el 5 de diciembre de 2019 en <https://www.laizquierdadiario.cl/El-desempleo-se-mantiene-y-Pinera-culpa-alos-migrantes $>$.

${ }^{8}$ Ibíd.

9 Vid. "Pablo Longueira: xenofobia, ignorancia y migración" de Luis Eduardo Thayer en El Mostrador. Consultado el 5 de diciembre de 2019 en <https://www.elmostrador.cl/noticias/opinion/2013/06/19/pablo-longueira-xenofobiaignorancia-y-migracion/>.
} 
pues si se revisan las cifras se percatará que los extranjeros constituyen un porcentaje menor del mercado de trabajo, ya que "solo el 1,5\% de los asalariados son migrantes y un $1,9 \%$ de los trabajadores por cuenta propia. Una diferencia está en el personal de servicio doméstico, donde su participación llega al $7 \%{ }^{\prime 10}$, por ende, su presencia no resulta significativa, empero no por ello deja de ser relevante.

A diferencia de lo que plantea Longueira, los foráneos constituyen un aporte a la economía chilena y muy relevante, pues con su trabajo no sólo suplen la mano de obra en ámbitos ya no requeridos por los nacionales, como el trabajo doméstico (Stefoni y Fernández 2011), sino que también posibilitan el crecimiento de la economía, al activarla. Por tanto, no es que su presencia reduzca el salario de los chilenos, más bien lo incrementa ${ }^{11}$. Asimismo, en Chile son un referente importante en áreas como la salud, donde la atención primaria "es cubierta en un $30 \%$ por médicos extranjeros, la mayoría ecuatorianos y colombianos" ${ }^{\prime 2}$.

Siguiendo a Thayer, la preocupación de los sectores conservadores por la supuesta ilegalidad y el aprovechamiento de los servicios públicos por parte de foráneos, revela que lo central es que la inmigración no se vincula primeramente ni con del desarrollo, ni con el trabajo ni con la seguridad nacional, sino con la garantía que tienen los sujetos de movilizarse y de acceder a la ciudadanía en igualdad de condiciones ${ }^{13}$. Lo cual, sin duda con retóricas de esta índole no es posible alcanzar, en la medida que en el plano público se imponen discursos restrictivos que en vez de atender a la premisa de tener derechos por el mero hecho de ser personas, apuestan por sujetar las garantías a los requerimientos de la economía.

Bajo un razonamiento similar, Sebastián Piñera el año 2016, siendo candidato presidencial declaró "por qué tenemos que dejar entrar cosas [sic] que le hacen mal al país. Puedo decidir quién quiero que entre a mi país"1 ${ }^{14}$. Esta frase, para Nanette Liberona, es de una arrogancia ignorante, puesto que asume que los Estados y sus mandatarios tienen la capacidad de controlar los flujos de personas, lo que sin duda excede de sus posibilidades, ya que en los tiempos actuales de globalización no es

${ }^{10}$ Cf. "Comisión de Trabajo revisa cifras de empleo con el INE y la Universidad de Chile", consultado el 19 de diciembre de 2019 en

$<$ https://www.camara.cl/prensa/noticias_detalle.aspx?prmid=129715>.

${ }^{11}$ Cf. "Pablo Longueira: xenofobia, ignorancia y migración", por "Luis Eduardo Thayer" en "El Mostrador". Consultado el 5 de diciembre de 2019 en

$<$ https://www.elmostrador.cl/noticias/opinion/2013/06/19/pablo-longueira-xenofobiaignorancia-y-migracion/>.

12 Ibíd.

${ }^{13}$ Ibíd.

${ }^{14}$ Cf. "Piñera y la migración: La ignorancia que hace daño" de Nanette Liberona, publicada en "El desconcierto" el 12 de mayo de 2017. Consultado el 5 de diciembre de 2019 en $<$ https://www.eldesconcierto.cl/2017/05/12/pinera-y-la-migracion-la-ignorancia-que-hacedano/>. 
posible controlar los desplazamientos, además cosifica a quienes arriban, como si en vez, de personas, fueran objetos de los que se puede disponer según la conveniencia. Liberona añade que la ignorancia del entonces candidato no sorprende, pero sí genera daño, pues discursos de esta índole promueven la proliferación de estereotipos y prejuicios sociales, incentivando un imaginario que relaciona ciertos extranjeros con criminalidad. Ello, según Liberona es xenofobia y racismo, nociones que han servido para justificar las más grandes barbaries de la humanidad, por eso previene que resulta "nefasto para nuestra sociedad seguir avalando estas opiniones, en particular si quien las emite pretende representarla"15.

También dentro de esta dinámica cabe mencionar los dichos de José Miguel Ossandón, que en diciembre del 2016 siendo candidato presidencial por la derecha, dicotomizó al migrante, manifestando que abrir las fronteras sin restricción constituye una falta de respeto a los foráneos que desean construir una vida digna, "aplicar un filtro a las personas con antecedentes que quieren entrar al país no es discriminarlos, sino ayudar a los inmigrantes para que no los estigmaticen a priori" ${ }^{16}$. Como si los estereotipos que se les adosan a quienes se desplazan se explicarían justamente por la apertura de los lindes, como si los prejuicios que recaen sobre los mismos se encontraran justificados. El discurso que efectúa este parlamentario es perverso porque considera a priori que existen los "buenos" y los "malos" extranjeros, e insta a los foráneos a asumir que sus compatriotas que incumplen la normativa nacional son los culpables de su estigmatización.

Por otra parte, a mediados de diciembre de 2016 el entonces candidato presidencial de centroizquierda Alejandro Guillier en el marco de la campaña electoral, al hablar sobre movilidad humana, señaló que él desde que era parlamentario viene "reclamando" y pidiéndole al Gobierno que se haga "cargo del desempleo que crece en la zona norte de Chile, la zona minera, (por) la enorme migración" ${ }^{\prime \prime \prime 17}$. Según el actual senador, la cesantía que experimenta la región nortina se debería a la presencia de foráneos. Si bien, los últimos datos publicados por el Departamento de extranjería y migración (DEM) dan cuenta que en dicha zona el porcentaje de foráneos es uno de los más altos del país, alcanzando según el último Censo el $11 \%$ en relación a la población total regional, el desempleo se encuentra en un $8 \%{ }^{18}$, una cifra levemente mayor a la tasa nacional que se sitúa en un $7,1 \%$,

\footnotetext{
15 Ibíd.
}

${ }^{16}$ Cf. "Ossandón defiende su discurso sobre inmigración", consultado el 5 de diciembre de 2019 en <https://www.elmostrador.cl/noticias/pais/2016/12/06/ossandon-defiende-sudiscurso-sobre-inmigracion-aplicar-un-filtro-a-las-personas-con-antecedentes-no-esdiscriminarlos-sino-ayudar-a-los-inmigrantes-para-que-no-los-estigmaticen/>.

${ }^{17}$ Cf. "Alejandro Guillier: "Chile necesita una política migratoria más selectiva"", consultado el 19 de diciembre de 2019 en <https://www.cooperativa.cl/noticias/pais/poblacion/inmigrantes/alejandro-guillier-chilenecesita-una-politica-migratoria-mas/2016-12-12/225518.html>.

18 Cf. "Disminuye la tasa de cesantía en la región de Antofagasta", consultado el 5 de diciembre de 2019 en 
pero de todos maneras se trata de un porcentaje bajo, que no tiene por qué vincularse a quienes se movilizan.

Luego, en mayo del 2017 en un seminario en Antofagasta Sebastián Piñera sostuvo que, si nuevamente llegase a la presidencia, "vamos a cerrar las puertas a todo lo que es malo para Chile: la delincuencia, el contrabando, el narcotráfico, la migración ilegal". Aseguró que "no soy xenófobo, pero sí creo que hay que tener sentido común, no tengo por qué aceptar a cualquier persona que quiera venir a Chile $^{\prime 19}$. Como se observa, nuevamente Piñera se intenta justificar negando su xenofobia, bajo el argumento de defender al país, como si el arribo de ciertos foráneos fuese pernicioso para Chile, como si su llegada sólo debiese aceptarse si reporta beneficios.

Posteriormente, en octubre del 2017, Guillier como candidato presidencial, afirmó en un programa radial, examinando la llegada de foráneos, que él representa a "una región tremendamente golpeada por la fuerte migración, como no ha habido políticas públicas adecuadas se nos ha agudizado ciertos conflictos ${ }^{20}$, en materia de salud, educación. De este modo, nuevamente asocia su presencia al agravamiento de determinadas problemáticas, que no son responsabilidad de quienes se desplazan, sino constituyen falencias producto de implementar un modelo neoliberal que no les garantiza a todos la prestación de servicios esenciales, sino a quienes se los pueden costear, y quienes no cuenten con los recursos deberán conformarse con servicios precarios, de mala calidad, tal como acontece en Chile con la educación, la salud, la vivienda, etc.

Como se observa, el discurso del miedo incide en periodos electorales, promoviendo la construcción de discursos racializadores que legitiman imaginarios respecto al inmigrante que no se condicen con la realidad.

\subsection{MINISTROS DE ESTADO}

Como se señaló supra, el entonces ministro de Hacienda, Felipe Larraín sostuvo el 2018 luego de las declaraciones dadas con el presidente de la República, sobre cesantía vinculada a la presencia de foráneos en Chile, que se podía afirmar con certeza que el incremento del desempleo se debía a la inmigración.

El Banco Central en su informe de Política Monetaria planteó que la migración "podría explicar, en principio, la desaceleración salarial". Es decir, este organismo fue bien cauto a la hora de establecer que podría haber una conexión causal con los

<https://www.diarioantofagasta.cl/regional/antofagasta/97097/disminuye-la-tasa-cesantia-laregion-antofagasta/>.

${ }^{19}$ Cf. "Piñera y migración: "No tengo por qué aceptar a cualquier persona que quiera venir a Chile"", consultado el 5 de diciembre de 2019 en <https://www.latercera.com/noticia/pineramigracion-no-aceptar-cualquier-persona-quiera-venir-chile/>.

${ }^{20}$ Cf. "Guillier: "Los inmigrantes están siendo una contribución en un país que disminuye su natalidad", consultado el 5 de diciembre de 2019 en

<https://www.adnradio.cl/noticias/nacional/guillier-los-inmigrantes-estan-siendo-unacontribucion-en-un-pais-que-disminuye-su-natalidad/20171004/nota/3598672.aspx>. 
salarios, empero no la vincula a desempleo, como el ministro del ramo. El informe más reciente que existe sobre esta temática es de Bravo y Urzúa, de ClapesUC, el cual precisa que no ha habido efectos ni en empleo ni en salarios por parte de la población extranjera $^{21}$.

También el transformar al migrante en el chivo expiatorio se puede observar, por ejemplo, en las palabras que Alfredo Moreno pronunció el 15 de marzo del 2018. El entonces ministro de desarrollo social del segundo gobierno de Piñera, señaló en un encuentro de empresarios, que "hoy día muchos de los problemas sociales que estamos viendo están relacionados con un flujo de inmigrantes importante" ${ }^{22}$. Esta afirmación es peligrosa y denota ignorancia, pues aparte de no condecirse con las cifras, fomenta una visión negativa de los flujos de personas y terminan convirtiendo a ciertos extranjeros en chivos expiatorios. Las palabras de Moreno son sesgadas ya que muestran una visión parcial de lo que podría implicar la movilidad humana, e irresponsables, porque provienen de una autoridad pública que en vez de abordar este fenómeno sociocultural con la seriedad y profundidad que se requiere, opta por el recurso más fácil: endosarle a quien proviene del exterior los conflictos sociales.

La apreciación del referido ministro es errónea, ya que quienes se desplazan a Chile no constituyen la causa de los problemas que enfrenta la sociedad chilena, más bien, éstos se podrían explicar por el neoliberalismo exacerbado que caracteriza el sistema vigente. Como advirtió el director del "Servicio Jesuita migrante", los "problemas no son los migrantes, son nuestra estructura social, los problemas de injusticia ${ }^{23 "}$. Dejar marginalizada a un porcentaje de la población es, más bien, lo que ocasionaría el malestar generalizado, seguir fomentando un sistema que promueve la desigualdad e inequidad es lo que acrecentaría los conflictos, privilegiar el lucro, la rentabilidad y la eficiencia ante las necesidades de las personas es lo que podría alentar la mantención de las falencias. Con estas declaraciones, como sostuvo el candidato a diputado Dauno Tótoro, "el ministro alimenta un discurso xenofóbico de odio y falso. Los campamentos son producto de este sistema que entrega sueldos

\footnotetext{
${ }^{21}$ Para mayor información vid. "Migrantes o migración: cuando el miedo le gana a la verdad", consultado el 19 de diciembre de 2019 en

$<$ https://www.elmostrador.cl/destacado/2019/01/09/migrantes-o-migracion-cuando-el-miedole-gana-a-la-verdad/>.

${ }^{22}$ Cf. "El debut con la pierna izquierda de Alfredo Moreno: "Hoy muchos de los problemas sociales que estamos teniendo tienen que ver con los flujos importantes de inmigrantes", consultado el 3 de diciembre de 2019 en

$<$ https://www.elmostrador.cl/noticias/pais/2018/03/15/el-debut-con-la-pierna-izquierda-dealfredo-moreno-hoy-muchos-de-los-problemas-sociales-que-estamos-teniendo-tienen-quever-con-los-flujos-importantes-de inmigrantes/>.

${ }^{23}$ Cf. "Cartel anti-inmigración que apareció en Santiago, atemoriza a inmigrantes [2017]", consultado el 10 de enero de 2019 en <https://www.youtube.com/watch?v=gIMTpx5c0G0>.
} 
miserables en jornadas laborales extenuantes, y que estigmatiza y criminaliza la pobreza" ${ }^{24}$.

No sólo este ministro ha responsabilizado a quienes se desplazan de las problemáticas, también el entonces ministro de salud, Emilio Santelices, en el contexto de informar del aumento de SIDA en Chile, afirmó el 14 de febrero 2019 que "han venido extranjeros con $\mathrm{VIH}$, y por ello se incrementó la cifra de pacientes. Lo que como Ministerio nos corresponde es focalizar estrategias complementarias e identificar esas poblaciones para pesquisarlos y tratarlos ${ }^{\prime 25}$. En otros términos, le imputó a los foráneos el aumento de los casos de este virus en el país.

Emilio Santelices fue criticado por los parlamentarios de la oposición, al igual que por migrantes, quienes acusaron que aquellas declaraciones eran irresponsables, en la medida que fomentaban la xenofobia, responsabilizándolos de las falencias de la escasa educación sexual de Chile. Zurita, integrante de la comunidad extranjera en Chile, señaló que "hay una evidente falta de políticas públicas para atacar el problema. Apuntar a la migración no se hace cargo de ese problema y, por el contrario, se instala como verdad un hecho que contribuye al rechazo de la comunidad migrante" ${ }^{26-27}$.

Estas declaraciones para Esteban Arévalo, abogado experto en materias legales sobre VIH/SIDA,

son inaceptables por un ministro que actúa como representante del Estado chileno, infringiendo la norma expresa de la ley y también normas de nivel constitucional, como la igualdad ante la ley. Infringe tratados internacionales que han sido ratificados por Chile y que forman parte de nuestro ordenamiento jurídico en cuanto a la no discriminación y a la

${ }^{24}$ Cf. "Discurso xenofóbico: Ministro de Piñera atribuye los problemas sociales a los inmigrantes", consultado el 5 de diciembre de 2019 en

<http://www.laizquierdadiario.cl/Discurso-xenofobico-Ministro-de-Pinera-atribuye-losproblemas-sociales-a-los-inmigrantes?id_rubrique $=1201>$.

${ }^{25}$ Cf. "Frívolo e irresponsable": diputados de oposición critican a ministro Santelices por vincular aumento de $\mathrm{VIH}$ con migrantes", consultado el 5 de diciembre de 2019 en $<$ https://www.latercera.com/politica/noticia/frivolo-e-irresponsable-diputados-oposicioncritican-ministro-santelices-vincular-aumento-vih-migrantes/530161/>.

${ }^{26}$ Cf. "Comunidades migrantes a Santelices: “¿Qué culpa tenemos de que no haya educación sexual en Chile?", consultado el 5 de diciembre de 2019 en <https://www.latercera.com/latercera-pm/noticia/comunidades-migrantes-santelices-culpa-tenemos-no-haya-educacionsexual-chile/530173/>.

${ }^{27}$ Para comprender por qué es vital que el Estado implemente una política de educación sexual vid. "120 pulsaciones por minutos" de Robin Campillo. Este excelente film retrata la lucha que a inicios de los noventa dio el colectivo "Act Up París" para hacer visible la necesidad de que el aparato público se haga cargo de la prevención y freno del $\mathrm{VIH}$, una enfermedad que en esa época ya marginalizaba a quienes la sufrían. El panorama actual no es muy distinto, pues aún continúa instalado en el imaginario social la idea de que quienes tienen SIDA se corresponden con los sectores más excluidos de la sociedad. 
protección de los derechos de las personas migrantes ${ }^{28}$.

Asimismo, el "Colegio de Médicos de Chile" se pronunció criticando los dichos de la referida autoridad, en tanto son afirmaciones erradas y estigmatizantes, asegurando que los nuevos casos reportados, en su mayoría, corresponden a población nacional ${ }^{29}$. De igual modo, Thayer planteó que quienes arriban "no causan ninguno de los males que se les imputa de forma irresponsable. Hasta la semana pasada se les acusaba de traer el $\mathrm{VIH}$. Son el depositario de todos los miedos generados por el modelo de desarrollo" ${ }^{\prime \prime 3}$. Una retórica que ha adoptado el gobierno en funciones, que responde a una estrategia comunicacional que fortalece, entre otros, un estado policial y la precarización laboral de quienes se desplazan.

\subsection{AUTORIDAD MIGRATORIA}

Álvaro Bellolio, el actual jefe del Departamento de extranjería y migración, en mayo del 2019 en un programa radial, al referirse a la medida que acepta pasaportes de venezolanos vencidos para realizar trámites migratorios, señaló que "a diferencia de la comunidad haitiana, la comunidad venezolana sí ha mostrado mucho interés en regularizar su situación, en pedir su visa y tener los temas al día" ${ }^{\prime \prime 3}$. De esta manera, la autoridad migratoria dicotomiza a ciertos extranjeros, planteando que mientras los que provienen de Venezuela sí han tenido preocupación por tener los papeles al día, los que llegan de Haití no habrían manifestado interés. Bellolio efectuó estas declaraciones a pesar de que los haitianos fueron los que más se inscribieron en el proceso de regularización extraordinaria. Luego de la inscripción miles de visas fueron aprobadas para haitianos sin comprobar los antecedentes, por lo que al acudir a buscarlas se les informaba que faltaba un documento, que regresarán posteriormente. Este problema es responsabilidad de las instituciones, no de quienes se desplazan.

Asimismo, Álvaro Bellolio al hablar sobre el concepto de "ordenar la casa" acuñado por la Administración de turno, aseveró que "la izquierda celebraba esta

${ }^{28}$ Cf. "Los dichos del ministro infringen la ley del SIDA": Las críticas a Santelices por atribuir el aumento del VIH a la población migrante", consultado el 5 de diciembre de 2019 en $<$ https://www.eldesconcierto.cl/2019/02/14/los-dichos-del-ministro-infringen-la-ley-del-sidalas-criticas-a-santelices-por-atribuir-el-aumento-del-vih-a-la-poblacion-migrante/>.

${ }^{29}$ Cf. "Experta en VIH desmiente a Santelices: "La mayoría de las cifras de nuevos contagios de VIH corresponden a chilenos", consultado el 5 de diciembre de 2019 en $<$ https://www.eldesconcierto.cl/2019/02/18/experta-en-vih-desmiente-a-santelices-lamayoria-de-las-cifras-de-nuevos-contagios-de-vih-corresponden-a-chilenos/>.

${ }^{30}$ Cf. "Luis Eduardo Thayer: "Los migrantes son el depositario de los miedos generados por el modelo de desarrollo", consultado el 5 de diciembre de 2019 en $<$ https://radio.uchile.cl/2018/12/18/luis-eduardo-thayer-los-migrantes-son-el-depositario-delos-miedos-generados-por-modelo-de-desarrollo/>.

${ }^{31}$ Cf. "La diáspora: el podcast de la comunidad venezolana en Chile", consultado el 5 de diciembre de 2019 en <https://ellibero.cl/audio/aceptar-los-pasaportes-vencidos-es-unejemplo-de-como-chile-se-preocupa-de-la-comunidad-venezolana-dice-alvaro-bellolio/>. 
lógica que pasó con la comunidad haitiana que llegaban como turistas y al final se quedaban irregular, se quedaban en las calles, desamparados, muchos de ellos justamente llorando por la oportunidad de volver a su país" ${ }^{\prime 32}$. De este modo, el jefe del DEM únicamente vincula a esta comunidad al incumplimiento de la ley, asociando a los haitianos a la irregularidad, siendo que es una situación en la que pueden encontrarse las más diversas comunidades foráneas. Además le adiciona un componente que no se condice con la realidad, este factor de abandono y de miseria que acompañaría a estos caribeños. Por eso esta Administración, como denuncian Sultant, Orrego y Calderón genera la "constante criminalización de las personas migrantes, la comparación tendenciosa entre el buen y el mal migrante y la desarticulación de espacios de participación de la población migrante y la sociedad civil con el Estado" ${ }^{\prime 3}$. Agregan que, "es la imagen que han instalado las autoridades sobre la migración y las personas que buscan establecerse en el país, explotándola cada vez que el Gobierno se ve cuestionado por la ciudadanía" ${ }^{\prime 34}$.

En efecto, la autoridad migratoria se vale del foráneo que representa la alteridad in extremis para adosarle la violación de la ley y la escasa intención de regularizarse, así el extranjero negro, pobre y que no habla castellano es configurado como una amenaza, como un sujeto que ocupa la vía pública y se mantiene en Chile incumpliendo la normativa. Una imagen que no se atiene a la realidad, pero que es utilizada eficientemente cuando lo requiere la política.

\subsection{AUTORIDAD REGIONAL}

El 2014 el entonces Intendente de la Segunda Región (máxima autoridad regional), Waldo Mora, vinculó a las mujeres foráneas que residen en dicha zona a enfermedades y trabajo sexual. Precisamente relacionó la llegada de colombianas con un aumento de enfermedades venéreas tales como gonorrea, sífilis y SIDA. El entonces gobernador señaló a un medio de prensa que "la prostitución en Antofagasta ha sido muy fuerte. Justamente mujeres colombianas, que dicho de paso son buena mozas, han llegado y es una prostitución tremenda en Antofagasta y es muy notorio" ${ }^{\prime 35}$. Así, transformando a las colombianas en chivos expiatorios, Mora

\footnotetext{
32 Ibíd.

33 Cf. "Efectos de la política migratoria: entre malas decisiones y las mentiras" por Edward Sultant, Cristián Orrego y Felipe Calderón, consultado el 5 de diciembre de 2019 en $<$ https://www.elmostrador.cl/noticias/opinion/2019/06/05/efectos-de-la-politica-migratoriaentre-malas-decisiones-y-las-mentiras/>.

34 Ibíd.

${ }^{35}$ Cf. "Waldo Mora: Prostitutas colombianas causaron aumento de enfermedades sexuales", consultado el 14 de diciembre de 2019 en<https:/www.cooperativa.cl/noticias/pais/regionde-antofagasta/waldo-mora-prostitutas-colombianas-causaron-aumento-deenfermedades/2014-08-11/163614.html>.
} 
aseguró que con su llegada aparecieron "enfermedades venéreas, enfermedades sociales que no se conocían" ${ }^{36}$.

Estos no han sido los únicos dichos del ex Intendente de la II Región, también planteó que las extranjeras eran motivo de quiebres matrimoniales, en tanto les quitarían el marido a las chilenas para mejorar su situación migratoria ${ }^{37}$.

Como advierte Gissi (2017), en Chile predomina el imaginario social que vincula narcotráfico a colombinas y sexualiza a las colombianas, hasta asociarlas a trabajadores sexuales. Algunas autoridades dicotomizan los flujos, como el parlamentario Lagos Cosgrove, que se refiere a la "invasión" de foráneos: "Hay invasiones que son satisfactorias, tienen que ver con el flujo turístico y hay otras no gratas relacionadas con la permanencia de ilegales que generan trastornos en el empleo" (Liberona, 2015a: 59). En este marco, el sociólogo Polloni se interroga si en la II Región, se estaría produciendo el comienzo de la administración política de la xenofobia, según su parecer sí, si se considera los siguientes elementos:

la actual alcaldesa de Antofagasta, quien sin desparpajo ha señalado que la migración es sinónimo de delincuencia y, siendo más sofisticada en su particularización, ella se refiere a la comunidad colombiana. Recordado es el anterior intendente también por su autorización de una marcha contra migrantes colombianos. Asimismo, senadores y diputados de la región se esmeran por proponer leyes restrictivas o muros simbólicos al fenómeno migratorio. O bien las explícitas aseveraciones como por ejemplo que 6 de cada 10 niños nacidos en Antofagasta son hijos de extranjeros, olvidando que todo niño o niña nacida en Chile por derechos es chileno. Tal vez la reproducción política de la xenofobia es el camino rápido ante la imposibilidad de la generación de estrategias institucionales de inclusión efectiva de las diversas comunidades residentes en Chile ${ }^{38}$.

Si se entiende xenofobia como "el rechazo o la exclusión de otra identidad cultural ajena por el mero hecho de ser tal" (Silveira, 1996: 135), lo que ha estado aconteciendo en dicha zona denota una retórica que se condice con efectuar un

\footnotetext{
36 Ibíd.
}

37 Cf. "Polémica: Intendente de Antofagasta acusa a extranjeros de crear "problemas de convivencia y quiebres matrimoniales" y programa de televisión Meganoticias "Inmigrantes en Antofagasta", consultados el 22 de enero de 2019 en

<https://www.theclinic.cl/2013/10/14/polemica-intendente-de-antofagasta-acusa-aextranjeros-de-crear-problemas-de-convivencia-y-quiebres-matrimoniales/> y en: $<$ https://bit.ly/2P9tkS6>.

${ }^{38}$ Cf. "Chile: ¿el inicio de la administración política de la xenofobia?", de Leonardo Polloni publicada en "El quinto poder" el 28 de abril de 2016. Consultado el 5 de diciembre de 2019 en

$<$ https://www.elquintopoder.cl/sociedad/chile-el-inicio-de-la-administracion-de-laxenofobia/>. 
juicio ex ante sobre un sujeto sin la necesidad de mostrar pruebas e incluso sin tener una experiencia previa con lo estigmatizado. Ello debido a que las declaraciones pronunciadas por las autoridades locales más que implicar una reflexión sobre las complejas problemáticas que se pueden dar en una sociedad pluricultural, se construyen a partir del miedo a lo distinto, de visualizar al otro como un inferior, como un sujeto que debe ser excluido.

Silva, Méndez, Echague y Rodríguez sistematizando las investigaciones sobre los extranjeros residentes en Antofagasta, observan que los afrocolombianos "deben demostrar que son "personas decentes" y que vienen a trabajar de manera digna, fundamentalmente porque los/as antofagastinos/as antes de conocerlos/as ya tienen un juicio negativo de ellos/as por ser colombianos/as y por ser negros/as" (2013: 68). Esta dinámica se exacerba aproximadamente desde el 2010 en adelante, período en que aumenta el arribo de personas de esta nacionalidad, una colectividad que presenta gran diversidad étnica. Precisamente el componente afrocolombiano que la caracteriza produce alta visibilidad en una sociedad autopercibida como blanca y homogénea. Esta falsa pretensión en que se asienta la comunidad local incide para que los cuerpos afrodescendientes sean visualizados como una transgresión en todo ámbito.

\subsection{AUTORIDADES LOCALES}

El año 2008 el alcalde de la comuna de Independencia en la Región Metropolitana, Antonio Garrido, señaló a un periódico nacional, cuando le preguntaron por los problemas que ocasionaba el alto número de peruanos en su comuna, que: "“¡Muchos! Los peruanos que han llegado no son de primera ni segunda, son de tercera categoría, vienen muertos de hambre (...) y traen sus costumbres, como comer y tomar en la calle. En Chile no estamos acostumbrados a la cochinada [suciedad]" ${ }^{\prime 39}$.

Dichas declaraciones le endosan al peruano características negativas que no tendrían los nacionales, por lo que su presencia resultaría molesta. Para la referida autoridad los peruanos al llegar con tradiciones diversas a los chilenos no enriquecería con su diversidad, asimismo, según Garrido al ser de la más baja categoría no se comportarían como es debido y terminarían ensuciando los espacios públicos.

En una línea similar, a fines del 2016, la edil de Antofagasta, Karen Rojo, declaró en un periódico nacional que "la población que está llegando está generando serios problemas $^{\prime \prime 40}$. Luego, en igual tono, en una presentación en el Congreso, sostuvo que: "no quiero en la comuna de Antofagasta guetos de pobreza y lamentablemente la población que está llegando está generando serios problemas que, si no los

\footnotetext{
39 Cf. "Denuncian al alcalde RN Antonio Garrido por regalar licencias de conducir", consultado el 5 de diciembre de 2019 en <https://bit.ly/2tkmssG>.

${ }^{40}$ Cf. "El negro historial de políticas de Karen Rojo, la alcaldesa de Antofagasta", consultado el 5 de diciembre de 2019 en <https://radio.uchile.cl/2017/10/30/el-negro-historial-depoliticas-de-karen-rojo-la-alcaldesa-de-antofagasta/>.
} 
tocamos a tiempo, esta situación va a ser irreparable ${ }^{\prime 41}$. El lenguaje de la alcaldesa denota un modo de visualizar al otro como una amenaza, como un riesgo al estilo de vida nacional, a las costumbres chilenas, a la estabilidad y a la seguridad. Los extranjeros, como advierte Bauman, "presagian el desmoronamiento y la desaparición del modo de vida que conocemos, practicamos y apreciamos" (2017: 9), por eso la respuesta frente a su llegada se sintetiza en rechazo. De ahí que, en esta región, la inmigración se gestionaría, como arguye Polloni, "más bien administrando políticamente la xenofobia, permitiendo de esta manera el fácil rédito político esperado" ${ }^{\prime \prime 2}$.

\section{A MODO DE CONCLUSIÓN}

En declaraciones de autoridades chilenas es posible percibir sesgos respecto de ciertas comunidades, dicotomizando a quienes se movilizan y transformándolos en chivos expiatorios, culpándolos del desempleo, de conductas que no se condecirían con el ser nacional, con escasa higiene, con conductas que vulneran la ley, etc. En este país se reproduce un falaz imaginario social que se nutre de retóricas de políticos que remarcan la separación entre los extranjeros y los autóctonos, reforzando la idea de que los segundos no debiesen gozar de los mismos derechos que los primeros, es decir, defienden una precarización en el acceso y disfrute de las garantías esenciales de los migrantes por su condición de foráneo.

Esta dinámica de acentuar los antagonismos entre la población nacional y la autóctona se efectúa con la finalidad de legitimar la restricción de los derechos de los migrantes y naturalizar una política que promueve una ciudadanía precaria. Una lógica que apuesta por configurar una alteridad respecto de quienes arriban que fomenta la discriminación y la segregación de los mismos, impidiendo cualquier posibilidad de acercamiento y encuentro. Estas retóricas terminan construyendo un imaginario social que devela que no existe reconocimiento, sino únicamente exclusión de un colectivo que se percibe como inferior.

El neoliberalismo ha posibilitado naturalizar lo anterior, exacerbando el individualismo hasta su máxima expresión y precarizando la vida en general, de ahí que en Chile adquieran fuerza discursos que abogan por los "autóctonos" y presentan a quienes se desplazan como enemigos que vendrían a medrar el bienestar, así determinados foráneos se convierten en el perfecto chivo expiatorio. Cuando se ha transformado al otro en una amenaza y lo común se ha perdido o se ha resquebrajado, como ha pasado en este país, es difícil no adoptar un discurso que privilegia lo "propio". Una retórica racista sobre la inmigración que se introduce en la esfera pública desde los albores de la República de Chile, pero cobra relevancia en las últimas décadas, en especial debido a la eclosión acontecida desde el 2000 en adelante.

${ }^{41}$ Ibíd.

${ }^{42}$ Cf. "Chile: ¿el inicio de la administración política de la xenofobia?", de Leonardo Polloni publicada en "El quinto poder" el 28 de abril de 2016. Consultado el 5 de diciembre de 2019 en<https://www.elquintopoder.cl/sociedad/chile-el-inicio-de-la-administracion-de-laxenofobia/>. 
Atendiendo a que el discurso cumple un papel trascendental en la reproducción de las relaciones de poder y de las identidades sociales, se debe propender a una conciencia crítica del lenguaje, que lo comprenda como una herramienta contra la exclusión. De ahí la necesidad de denunciar estas retóricas discriminadoras que le adosan a los migrantes las falencias sociales, fomentando un imaginario segregador que no posibilita su inclusión integral. En la medida que las figuras políticas continúen con discursos de esta índole, la reproducción de prejuicios y estereotipos respecto a los que arriban seguirá in crescendo. Por ende, es fundamental que las autoridades en el desempeño de su labor actúen con responsabilidad evitando declaraciones que no hacen más que exacerbar la diferencia y el malestar. Por su cargo, los funcionarios de la Administración del Estado y del gobierno debiesen comprender que los migrantes son personas que por su calidad de tal tienen derechos que deben ser respetados, y en vez de azuzar los temores de la sociedad, propender a la protección de las garantías esenciales de todos quienes habitan el territorio. Rechazar una ciudadanía precaria es una premisa que debiese adoptarse en toda democracia que se precie de tal.

\section{BiBLIOGRAFÍA}

BAUMAN, Zygmunt. (2017). Extraños Ilamando a la puerta. Barcelona: Paidós.

CORREA, Josefina. (2011). Ser "inmigrante" en Chile: la experiencia del racismo cotidiano de peruanos y peruanas en la ciudad de Santiago (tesis de pregrado). Universidad de Chile, Santiago, Chile.

DÍAZ, Javiera. (2015). "Democracia y Estado de Derecho en Chile. Análisis de las transformaciones constitucionales y del derecho penal en el período 1973-2011" (tesis doctoral). Universidad de Barcelona, Barcelona.

FAIRCLOUGH, Norman. (2008). "El análisis crítico del discurso y la mercantilización del discurso público: las universidades". Discurso y Sociedad, 2 (1), pp. 170-185.

FAIRCLOUGH, Norman. y WODAK, Ruth. (2000). "Análisis crítico del discurso", en VAN DIJK, Teun (Comp.), El discurso como interacción social. Estudios sobre el discurso. Una introducción multidisciplinaria. Barcelona: Gedisa.

FERRAJOLI, Luigi. (2014). “Criminología, crímenes globales y derecho penal. El debate epistemológico en la criminología contemporánea", en RIVERA, José. (Coord.), Delitos de los estados, de los mercados y daño social. Barcelona: Anthropos.

GISSI, Nicolás. (2017). DEM Investiga. Estudio del proceso de integración y exclusión de los inmigrantes colombianos en la Región Metropolitana de Chile. Departamento 
de Extranjería e inmigración del Ministerio del Interior y Seguridad Pública. Santiago de Chile. Consultado el 19 de diciembre de 2019 en https://www.extranjeria.gob.cl/media/2019/04/DEMlnvestiga2EstudiodelProcesodelnt egracionyExclusiondelosInmigrantesColombianosenlaRegionMetropolitanaChile.pdf

JAMESON, Fredric. (1998). "Sobre los estudios culturales", en JAMESON, Fredric y Žižek Slavoj. (Ed.), Estudios Culturales: Reflexiones sobre el multiculturalismo. Buenos Aires: Paidós.

LIBERONA, Nanette. (2015a). "De las fronteras geopolíticas a las fronteras sociales. La migración boliviana a través de la prensa de Tarapacá (1990-2007)". Estudios Fronterizos, 16 (32), pp. 41-74.

LIBERONA, Nanette. (2015b). Prácticas institucionales racistas en el ingreso de migrantes a Chile y la Ilegalidad. En Las antropologías latinoamericanas frente a un mundo de transición. Simposio llevado a cabo en IV Congreso Latinoamericano de Antropología en México, Ciudad de México.

MÁRQUEZ, Francisca y CORREA, Juan. (2015). "Identidades, arraigos y soberanías: Migración peruana en Santiago de Chile". Polis Revista Latinoamericana, 14 (42), pp. 167-189.

PÓO, Ximena. (2009). "Imaginarios sobre inmigración peruana en la prensa escrita chilena: una mirada a la instalación de la agenda de la diferencia". Revista F@ro, (9), pp. 1-9.

SILVA, Jimena, MÉNDEZ, Leyla, ECHAGUE, Clive y RODRíGUEZ, Germán. (2013). Inmigrantes en Antofagasta. Sistematización de investigaciones realizadas sobre la situación de inmigración latinoamericana en la Región. Universidad Católica del Norte y Servicio Jesuita Migrantes. Consultado el 19 de diciembre de 2019 en https://www.researchgate.net/publication/284445912_Inmigrantes_en_Antofagasta_S istematizacion_de_investigaciones_realizadas_sobre_la_situacion_de_inmigracion_la tinoamericana_en_la_Region-2013

SILVEIRA, Héctor. (2012). "Biopolítica de Estados Expulsores". Revista Científica Complutense Política y Sociedad, 49 (3), pp. 497-517.

SILVEIRA, Héctor (1996). "La exclusión del otro extranjero y la democracia de las diferencias". En AA.VV., El límite de los derechos. Barcelona: Eub. 
STEFONI, Carolina y FERNÁNDEZ, Rosario. (2011). "Mujeres inmigrantes en el trabajo doméstico: entre el servilismo y los derechos", en STEFONI, Carolina (Ed.), Mujeres inmigrantes en Chile ¿Mano de obra o trabajadoras con derecho? Santiago: Ediciones Universidad Alberto Hurtado.

TIJOUX, María y DÍAZ, Gonzalo. (2014). "Inmigrantes, los "nuevos bárbaros" en la gramática biopolítica de los estados contemporáneos". Rivista Internazionale di Filosofia Contemporanea, 2 (1), pp. 284-309.

VAN DIJK, Teun. (1988). "El discurso y la reproducción del racismo". Lenguaje en contexto, 1 (1-2), pp. 131-180.

WIEVIORKA, Michel. (1992). El espacio del racismo. Barcelona: Paidós.

ZAVALA, Ximena y ROJAS, Claudia. (2005). "Globalización, procesos migratorios y Estado en Chile", en Programa mujeres y movimientos sociales en el marco de los procesos de integración regional en América Latina, apoyado por la Fundación Heinrich Böll. Migraciones, globalización y género en Argentina y Chile. Buenos Aires: Heinrich Böll. 